\title{
The Classification of Aggressive Dialogue in Social Media Platforms
}

\author{
Jaida Langham \\ Spelman College \\ Department of Computer and Information Sciences \\ Atlanta, GA, USA \\ jlangham@scmail.spelman.edu
}

\author{
Kinnis Gosha \\ Morehouse College \\ Department of Computer Science \\ Atlanta, GA, USA \\ kinnis.gosha@morehouse.edu
}

\begin{abstract}
The significance of aggression for the understanding of human behavior cannot be over amplified. It associates the individual, behavior, habits, environment, and health (mental). Understanding specificity when it comes to types of aggression and aggressive behavior can help with implementing appropriate countermeasures to those who demonstrate aggressive behavior within their speech and behavior on social media platforms. Through a research synthesis utilizing different search engines to find work on hate speech detection, hate, anger, aggressive behavior in social media, and the consequences associated with these terms, it can be concluded that previous work on hate speech detection have developed methods that ignore the variety in speech, possible other categories of hate speech, the correlation of speech to human behavior, and demonstrate minimal to no empathy toward the users from which this data was extracted from. Categorizations of hate speech currently only include hate and offensive language. Another category that should be added is anger. Future studies should specify their searches to including aggressive behavior since it is the connection when analyzing human behavior and hate speech.
\end{abstract}

\section{CCS CONCEPTS}

- Social and professional topics $\rightarrow$ Hate speech; • Information systems $\rightarrow$ Social networks;

\section{KEYWORDS}

Aggressive behavior, anger, hate, offensive language, social media, violence, hate speech

\section{ACM Reference Format:}

Jaida Langham and Kinnis Gosha. 2018. The Classification of Aggressive Dialogue in Social Media Platforms. In SIGMIS-CPR '18: 2018 Computers and People Research Conference, June 18-20, 2018, Buffalo-Niagara Falls, NY, USA. ACM, New York, NY, USA, 4 pages. https://doi.org/10.1145/3209626.3209720

\section{INTRODUCTION}

There have been several unfortunate cases of social media serving as a tool leading to suicides, murders and violence - especially with

Permission to make digital or hard copies of all or part of this work for personal or classroom use is granted without fee provided that copies are not made or distributed for profit or commercial advantage and that copies bear this notice and the full citation on the first page. Copyrights for components of this work owned by others than ACM must be honored. Abstracting with credit is permitted. To copy otherwise, or republish, to post on servers or to redistribute to lists, requires prior specific permission and/or a fee. Request permissions from permissions@acm.org.

SIGMIS-CPR '18, fune 18-20, 2018, Buffalo-Niagara Falls, NY, USA

(c) 2018 Association for Computing Machinery.

ACM ISBN 978-1-4503-5768-5/18/06 . \$15.00

https://doi.org/10.1145/3209626.3209720 teenagers and young adults [5, 8, 9, 14-18, 22, 25, 28, 29, 31], largely in part because of hate speech. Hate speech is considered an epidemic and as a primary tool in inciting violence onto others through various platforms [23]. In 2017, one of the largest social media firms, Twitter, adjusted their privacy policy rules pertaining to abusive behavior. This includes any tweet that promotes violence, self-harm, suicide, harassment, abuse, hate, and so on. [32] The problem is that current detection implementations that are used to support policies implemented to govern user language and interactions, ignore the multifaceted attributes of speech and negative aggressive behavior which leads to inaccurate categorizations and generalizations. A demonstration of hate speech is a confirmation of the presence of negative aggressive behavior within a user. Negative aggressive behavior includes offensive language, hate, and anger [21]. Currently, there is no consolidated way to detect anger within social media. A majority of the previous work that has focused on hate speech has attempted to detect hate speech in a binary method, meaning the tweet/post/comment is flagged for hate or not. A 2017 study on hate speech detection brought to light another category, offensive language, with a method that was used to categorize a tweet/post/comment into the categories of hate, offensive language, or neither. [11] Although this method considers hate speech as larger than a binary system, this method still ignores the variety in speech, possible other categories of hate speech, and demonstrates minimal to no empathy toward the users from which this data was extracted from. In 2013, there was a study conducted on the Chinese "Twitter"-like social media platform that concluded that anger is the most influential social media emotion. [13] Multiple studies have shown how anger in social media becomes contagious from one from user to another. [2, 12, 13, 19, 30, 35] Anger is inevitably heavily involved in the hate crimes, bullying, suicides, deaths, fights, and murders in social media. In this study, we argue that Anger should be considered in hate speech detection methods because it will effectively assist in proper categorization. The goal of this paper is to review the literature and develop a more accurate and inclusive classification of anger-related social media posts to be used for hate speech detection. Acknowledgment of the impact of negative aggressive behavior and the role of anger in hate speech is necessary for reducing aggressive behavior within social media and deciding the appropriate countermeasures for those who demonstrate it. 


\section{BACKGROUND}

When discussing the flaws within a detection method used to categorize humans, the human behavior must be considered. The overarching category that includes hate speech, behavioral problems, anger, offensive language, and so on is the category of aggressive human behavior. A better understanding of aggression is necessary for learning how to prevent negative aggression in the future. Aggression can be applied to animal behavior as well as human behavior. When applied to human behavior, it is used to describe personality and attitudes, as well as to characterize behavior in both children and adults. Certain levels of aggression are considered unhealthy. $[3,21]$ Examples of difference in levels and context of aggression include the "aggressive" businessman, which is used in a daily context to designate forceful but legitimate actions or the "aggressive" and uncooperative man which is used in a context that denotes negative, antagonistic, and maybe even hostile actions of that man. It is important to consider the complex and multifaceted nature of aggression strictly because of differences in catalysts, psychological development, mental processes and so on. [21] The aggressive behavior that is commonly referred to in this paper can be defined as hostile, negative, inappropriate aggression, meaning its purpose is to induce injury or pain.

As stated before, negative aggressive behavior includes demonstrations of hate. Previous studies on hate and hate speech generalize hate to this one large idea of anything that has a negative context - hate vs. neither-, innately ignoring the diversity of emotions and human behavior. Anger and hatred are interrelated, but different in definition and behavior. Anger is an initial reaction to something and is also a more temporary emotion. Hatred is a more sustained, possibly permanent, reaction to something. [7] For example, you can be angry at someone for cutting you off in traffic, but maybe a few hours later, you won't be necessarily angry at that person anymore; but you can say that you hate being cut off in traffic in general. Anger and hatred exist on the same scale but are different in intensity and energy.

The general term used to describe aggressive behavior on social media is "hate speech." To define hate speech, the definition of hate in a social context must also be considered. The word "hate" can be understood as "extreme negative feelings and beliefs held about a group of individuals or a specific representative of that group because of their race, ethnicity, religion, gender or sexual orientation".[26] The term "hate speech" can be understood as covering all forms of expression that "spread, incite, promote or justify racial hatred, xenophobia, anti-Semitism or other forms of hatred based on intolerance, including intolerance expressed by aggressive nationalism and ethnocentrism, discrimination and hostility against minorities, migrants and people of immigrant origin”.[24] Referring to these definitions, hate is a broad category that covers a large spectrum of potential tweet context but not all. A user can create a negative tweet that does not demonstrate hatred based on another's identity. People often use terms that are highly offensive to certain groups but in a qualitatively different manner. [11] A definition of offensive language can be generalized to mean language used in an amicable manner that does not intend for offense. For example,
African Americans using the term $\mathrm{n}^{*}$ gga in daily online language [34], other profane terms such as $b^{*} t c h, h^{*} e, c^{*} n t$, *sshole, are used in quoting song lyrics and during affable conversations between peers. Profane language is common on social media and is seen as a normality [33], such that the category of offensive language is considered during hate speech detection. Anger is not an example of hate nor offensive language but is interrelated. For example, Team A just beat Team $B$ in a sports game, fans of Team $B$ goes to the main blog for fans of Team B and makes the comment "Team A is full of a bunch of $b^{*}$ tches," the word $b^{*}$ tch suggests offensive language but it is not, because the context was meant to be intentionally offensive; hate would not be a proper category either because this post did not promote hatred based on Team A's identity; anger would be the proper category because Team B posted this as an emotional response to losing the game and Team A's post. Fights, murders, suicides, are consequences of emotional responses like anger. For example, you fight someone because they offended you. You murder someone because they offended you deeply, inciting a large angry response.

Social media and other internet outlets have given freedom of expression a much larger platform [4]. Within this new platform, hate, anger, offensive language, and other examples of aggressive behavior can be shared freely. A common example of aggressive behavior within social media is trolling. Trolling means to "make a deliberately offensive or provocative online post with the aim of upsetting someone or eliciting an angry response from them" [1]. These angry responses turn into online arguments and debates which in some cases is contagious and can spread from user to user, especially on platforms like Twitter. Twitter gives users the options to like and to retweet tweets, both of which generally demonstrate unison or assent with each other in agreement with context. If a user tweets something hateful, offensive or even angry, there is an opportunity for other users to agree or speak out against with a reply or quote; these responses could potentially include profane language said in a manner to incite offense, whether the response includes a targeting based on the identity of the other user would determine if it is hate or anger. Sadly, not all free speech has positive implications [23]. Freedom of speech has created a hostile environment for many people [23]. Because of this growing issue [4], detection methods are relied on so executive decisions can be made and policies implemented to make the internet environment safer for the users. Social media platforms, like Twitter, have a reputation to randomly suspend accounts due to detection of spam, post-stealing, and improper or abusive language. [6, 20, 27, 32] Heavy reliance on detection methods leaves the platform vulnerable to error, because if the detection method is flawed or inaccurate, then users accounts will be shut down unjustly.

\section{RESEARCH APPROACH}

The goal of this paper is to review the literature and develop a more accurate and inclusive classification of anger-related social media post to be used for hate speech detection. Many people confuse a literature review with a research synthesis. According to Cooper [10], literature reviews can have one or more goals: to integrate (compare and contrast) what others have done and said, to criticize 
previous scholarly works, to build bridges between related topic areas, and/or to identify the central issues in a field. [10] The research approach for this paper follows along with the literature review goals outlined by Cooper [10]. The specific approach followed involved researching a topic, finding an area within that topic that could be expanded, formulating a hypothesis, researching keyword terms in specific search engines including Google, Google Scholar, ACM digital library, and integrating past research with the research findings and drawing overall conclusions related to the hypothesis.

\section{RESULTS FROM REVIEW}

Online blogs and news posts have discussed the power of anger and its influence in social media for the past five years [12, 13, 19, 30, 35], but there is hardly any published work relating anger and social media. Currently, studies do not consider anger as a plausible category to examine when detecting hate speech and analyzing social interactions, even with the vast amount of consequences that anger has presented in society. Table 1 can quantitatively show our findings after reviewing the literature.

In addition, there has been a scarce amount of published work relating aggressive behavior with computer-related social interactions. Hate speech relates to human behavior because it is an example of aggressive behavior. Ignoring the concept of aggressive behavior is an injustice to the studies of hate speech because it disregards the human aspect of the study. Overall, previous studies and papers are strictly focused on detecting hate language but have failed to acknowledge the variety of behaviors and emotions of the users and specify the category of human behavior that the study is focused on.

\section{CONCLUSION}

Future studies in hate speech detection should adopt our hypothesis of including anger in their detection methods and including an analysis of aggressive behavior in social media. When evaluating human and computer interaction, human behavior must be considered. Considering aggressive behavior as the overarching category puts a study into a better perspective when evaluating human behavior; aggressive behavior isn't a subcategory of hate, hate is a subcategory of aggressive behavior. Analyzing aggressive behavior in social media caters to the homogeneity of the users rather than strictly analyzing hate speech because it also considers offensive language, hate, anger, and other potential categories as well. Hate is interrelated with anger and offensive language. Hate

Table 1: Quantitative results from review

\begin{tabular}{|l|l|l|l|}
\hline & $\begin{array}{l}\text { Journal/ } \\
\text { Conference } \\
\text { Papers }\end{array}$ & $\begin{array}{l}\text { News } \\
\text { Articles/ } \\
\text { Editorials }\end{array}$ & Reports \\
\hline $\begin{array}{l}\text { Offensive } \\
\text { Language }\end{array}$ & 3 & 4 & 1 \\
\hline Hate & 8 & 15 & 4 \\
\hline Anger & 0 & 9 & 5 \\
\hline
\end{tabular}

is a demonstration of negative emotions and actions toward someone because of their identity. Anger and offensive language are also demonstrations of negativity, but anger is intentional while offensive language could be considered non-intentional due to the qualitative manner it is used. These studies should also consider referencing the definitions located in table 2 which gives a definition, detection method, and an example statement to aid them within these analytical studies and algorithm building. The addition of anger in speech analysis and aggressive behavior as a concept allows the studies to be more specific in their analyses of certain user data. Being able to specifically analyze the intent of users posts and categorize the specific type of aggression opens the door to providing appropriate countermeasures to the users and provides properly organized and categorized data that can be used for future studies.

\section{REFERENCES}

[1] 2018. Trolling. https://www.merriam-webster.com

[2] Roy F Baumeister, Ellen Bratslavsky, Catrin Finkenauer, and Kathleen D Vohs. 2001. Bad is stronger than good. Review of general psychology 5, 4 (2001), 323.

[3] Leonard Berkowitz. 1993. Aggression: Its causes, consequences, and control. Mcgraw-Hill Book Company.

[4] Michal Bilewicz. 2018. A lecture: Hate speech Epidemics. Are We Far from March '68? http://www.polin.pl/en/event/ a-lecture-hate-speech-epidemics-are-we-far-from-march-68

[5] Brittany Bostic. 2014. Does Social Media Perpetuate Youth Violence? http: //yvpc.sph.umich.edu/social-media-perpetuate-youth-violence/

[6] Russell Brandom and Casey Newton. 2017. Twitter is locking accounts that swear at famous people. https:/www.theverge.com/2017/2/24/14719828/ twitter-account-lock-ban-swearing-abuse-moderation

[7] Joseph Burgo. 2013. The Difference Between Anger and Hatred. http://www. afterpsychotherapy.com/anger-vs-hatred/

[8] CBS/AP. 2016. Cyberbullying pushed Texas teen to commit suicide, family says. https:/www.cbsnews.com/news/ cyberbullying-pushed-texas-teen-commit-suicide-family/

[9] Elizabeth Chuck. 2017. Is Social Media Contributing to Rising Teen Suicide Rate. https://www.nbcnews.com/news/us-news/ social-media-contributing-rising-teen-suicide-rate-n 812426

[10] Harris Cooper. 2009. Research Synthesis and Meta-Analysis: A Step-by-Step Approach. SAGE.

[11] Thomas Davidson, Dana Warmsley, Michael Macy, and Ingmar Weber. 2017. Automated hate speech detection and the problem of offensive language. arXiv preprint arXiv:1703.04009 (2017).

[12] Nick English. 2013. Anger is the Internet's most powerful emotion. https://www.usatoday.com/story/news/nation/2013/09/24/ anger-internet-most-powerful-emotion/2863869/

[13] Rui Fan, Jichang Zhao, Yan Chen, and Ke Xu. 2014. Anger is more influential than joy: Sentiment correlation in Weibo. PloS one 9, 10 (2014), e110184.

[14] Natsuko Fukue. 2017. 'Social media suicide' in spotlight after Japan 'Twitter killer'. https://phys.org/news/2017-11-social-media- suicide-spotlight-japan.html

[15] Meredith E. Gansner. 2017. "The Internet Made Me Do It"-Social Media and Potential for Violence in Adolescents.". http://www.psychiatrictimes.com/blogs/ internet-made-me-do-it-social-media-potential-violence-adolescents

[16] Jennifer Holladay. 2010. The stakes have never been higher for studentsâĂTor schools. teaching tolerance (2010).

[17] Julia Jacobo. 2017. Family of cyber-bullied NJ girl who killed herself to sue school district for negligence. https://abcnews.go.com/US/ family-cyber-bullied-nj-girl-killed-sue- school/story?id=48969586

[18] Tamara Jones. 2008. A Deadly Web of Deceit: A Teen's Online 'Friend' Proved False, And Cyber-Vigilantes Are Avenging Her. http://www.washingtonpost. com/wp-dyn/content/article/2008/01/09/AR2008010903367_pf.html

[19] Karen Pezza Leith and Roy F Baumeister. 1996. Why do bad moods increase self-defeating behavior? Emotion, risk tasking, and self-regulation. Fournal of personality and social psychology 71, 6 (1996), 1250.

[20] Andrew Liptak. 2018. Twitter has suspended a number of accounts responsible for 'tweetdecking'. https://www.theverge.com/2018/3/11/17107192/ twitter-tweetdecking-spam-suspended-accounts-mass-retweeting

[21] Jianghong Liu. 2004. Concept analysis: aggression. Issues in mental health nursing 25, 7 (2004), 693-714.

[22] David D Luxton, Jennifer D June, and Jonathan M Fairall. 2012. Social media and suicide: a public health perspective. American journal of public health 102, S2 
Table 2: Definition and detection method reference

\begin{tabular}{|c|c|c|c|}
\hline Category & Definition & Detection Method & Example \\
\hline Aggressive Speech & $\begin{array}{l}\text { Any speech or language that } \\
\text { demonstrates violence \&/or } \\
\text { induces (with or without intention) } \\
\text { pain, harm, embarrassment, or injury. }\end{array}$ & $\begin{array}{l}\text { Any examples of offensive language, hate or } \\
\text { anger. }\end{array}$ & $\begin{array}{l}\text { "Next person to bother me, is getting punched in } \\
\text { the face" }\end{array}$ \\
\hline \multirow{3}{*}{ Offensive Language } & \multirow{3}{*}{$\begin{array}{l}\text { Speech or language that } \\
\text { could unintentionally offend, } \\
\text { harm, or embarrass. }\end{array}$} & \multirow{3}{*}{$\begin{array}{l}\text { Specific terms that are deemed } \\
\text { as offensive or hateful, but } \\
\text { context and user profile is } \\
\text { considered. }\end{array}$} & (Woman to another woman) \\
\hline & & & $\begin{array}{l}\text { "You look so good b*tch" } \\
\text { (AA to another AA) }\end{array}$ \\
\hline & & & $\begin{array}{l}\text { "Whatsup my n*gga" } \\
\text { "I can't stand n"ggers" }\end{array}$ \\
\hline Hate & $\begin{array}{l}\text { Speech or language with the } \\
\text { purpose to offend, harm, or } \\
\text { embarrass a targeted group } \\
\text { based on their identity. }\end{array}$ & $\begin{array}{l}\text { Specific terms that are deemed } \\
\text { as offensive or hateful that } \\
\text { include offensive terms or } \\
\text { offensive context related to the } \\
\text { identity of a person or group. }\end{array}$ & $\begin{array}{l}\text { "Black people annoy me } \\
\text { always begging for handouts } \\
\text { and affirmative action. Get out } \\
\text { of my country!" }\end{array}$ \\
\hline Anger & $\begin{array}{l}\text { Speech or language with the } \\
\text { purpose of offending, harming, } \\
\text { or embarrassing. }\end{array}$ & $\begin{array}{l}\text { Specific terms that are deemed } \\
\text { as offensive or hateful. }\end{array}$ & "Everyone can go jump off of a bridge" \\
\hline
\end{tabular}

(2012), S195-S200.

[23] Toni M Massaro. 1990. Equality and freedom of expression: The hate speech dilemma. Wm. \& Mary L. Rev. 32 (1990), 211.

[24] Council of Europe. [n. d.]. Freedom of expression and information. https://www.coe.int/en/web/freedom-expression/ freedom-of-expression-and-information-explanatory-memo

[25] Desmond Upton Patton, Jun Sung Hong, Megan Ranney, Sadiq Patel, Caitlin Kelley, Rob Eschmann, and Tyreasa Washington. 2014. Social media as a vector for youth violence: A review of the literature. Computers in Human Behavior 35 (2014), 548-553.

[26] Barbara Perry. 2002. In the name of hate: Understanding hate crimes. Routledge.

[27] Harry Pettit. 2017. Twitter's Time Out: Site's New Tool BLOCKS Users for 12 Hours for Abusive Behaviour. http://www.dailymail.co.uk/sciencetech/ article-4230460/Twitter-blocking-users-12-hours.html

[28] Associated Press. 2017. Rise in teen suicide connected to social media popularity: study. $\quad$ https://nypost.com/2017/11/14/ rise-in-teen-suicide-connected-to-social-media-popularity-study/

[29] Samantha Schmidt. 2017. After months of bullying, her parents say, a 12-year-old New Jersey girl killed herself. They blame the school. https://www.washingtonpost.com/news/morning-mix/wp/2017/08/02/ after-months-of-bullying-a-12-year-old-new-jersey-girl-killed-herself-her-parentsblame-the-school/ ?noredirect=on\&utm term $=.4 \mathrm{f} 2154 \mathrm{c} 5911 \mathrm{f}$

[30] Susanna Schrobsdorff. 2017. The Rage Flu: Why All This Anger Is Contagious and Making us Sick. http://time.com/4838673/anger-and-partisanship-as-a-virus/

[31] TeenSafe. 2016. Suicide Now the Second Leading Cause of Death For Teens; Is Social Media to Blame? https://www.teensafe.com/blog/ suicide-now-second-leading-cause-death-teens-social-media-blame/

[32] Twitter. [n.d.]. The Twitter Rules. https://help.twitter.com/en/rules-and-policies/ twitter-rules.

[33] Wenbo Wang, Lu Chen, Krishnaprasad Thirunarayan, and Amit P Sheth. 2014. Cursing in english on twitter. In Proceedings of the 17th ACM conference on Computer supported cooperative work \& social computing. ACM, 415-425.

[34] William Warner and Julia Hirschberg. 2012. Detecting hate speech on the world wide web. In Proceedings of the Second Workshop on Language in Social Media. Association for Computational Linguistics, 19-26.

[35] Zoe Williams. 2017. We are all angry on social media âĂŞ at least try to listen to the rage of others. https:/www.theguardian.com/commentisfree/2017/oct/09/ angry-social-media-facebook-twitter-silicon-valley 